Objective To evaluate the efficacy of pentaglobulin in reducing the rate of exchange transfusion among neonates with immune hemolytic anaemia.

Method An observational prospective study that was conducted over two year's period starting from January 2010 to January 2012. Pentaglobulin was given in a dose of $1 \mathrm{gm} / \mathrm{Kg} /$ day for all newborns with the following criteria: immune hemolytic anaemia; high or rising level of bilirubin approaching exchange transfusion. Phototherapy was used in conjunction with pentaglobulin.

Results The total number of newborns who received pentaglobulin over that period of time was 85 infants. None of them required exchange transfusion. Ten newborns required top up transfusion. The duration of phototherapy application ranged from 48 to 72 hours.

Conclusion The study shows that early use of pentaglobulin in immune hemolytic anaemia reduces the risk of exchange transfusion and the duration of phototherapy application. Further randomized controlled trials are needed to verify the results of our observations.

\section{VITAMIN B12 AND FOLATE DEFICIENCY IN HEALTHY NEONATES AND THEIR MOTHERS}

doi:10.1136/archdischild-2012-302724.0763

${ }^{1} \mathrm{~F}$ Guven, ${ }^{2} \mathrm{~A}$ Say, ${ }^{2} \mathrm{~N}$ Uygur Kulcu, ${ }^{2} \mathrm{~S}$ Nepesov, ${ }^{2} \mathrm{M}$ Inalhan, ${ }^{2} \mathrm{~S}$ Degirmenci, ${ }^{2} \mathrm{TA}$ Sabuncu. 'Zeynep Kamil Maternity and Childrens' Disease Training and Research State Hospital, Isparta; 'Zeynep Kamil Maternity and Childrens' Disease Training and Research State Hospital, Istanbul, Turkey

Background and Aim We aimed to determine the incidence of vitamin B12 and folate deficiency in healthy neonates and their mothers; to show the correlation between maternal and neonatal B12 and folate levels.

Method The study consisted of 99 healthy neonates and their mothers who gave birth in Zeynep Kamil Maternity and Children Training and Research Hospital, İstanbul. Hospital records were reviewed and blood samples were obtained from both mothers and their babies in the 24 hours after birth. Serum vitamin B12 and folate levels were measured. SPSS 15.0 package program was used for statistical analysis.

Results The mean values were as follows: in mothers serum vitamin B12 level 180.84 $\pm 58.81 \mathrm{pg} / \mathrm{dl}$ and folate level 17.61 \pm 20.61 $\mathrm{nmol} / \mathrm{L}$; in neonates vitamin B12: $320.43 \pm 187.48 \mathrm{pg} / \mathrm{dl}$ and folate: $26.05 \pm 34.45 \mathrm{nmol} / \mathrm{L}$. There was significant correlation between maternal and neonatal folate levels but a slight correlation between maternal and neonatal B12 levels. $97 \%$ of mothers and $25.3 \%$ of neonates had B12 deficiency when the threshold level is defined as $300 \mathrm{pg} / \mathrm{ml}$ for mothers and $200 \mathrm{pg} / \mathrm{dl}$ for neonates.

Conclusion Due to high vitamin B12 deficiency rate in mothers a universal B12 vitamin screening program and preventative measures of B12 deficiency in pregnant women can reduce the potential complications of vitamin B12 deficiency in mothers and their siblings.

\section{A STUDY ON THE OUTCOME OF DIRECT COOMBS TEST (DCT) POSITIVE NEONATES}

doi:10.1136/archdischild-2012-302724.0764

KM Upatissa, J Greenaway, S Mahadevan-Bava. Paediatrics, Russells Hall Hospital, Dudley, UK

The management and follow up of neonates with DCT + differ from one centre to another. At RHH, guidelines recommend twice weekly FBC and Bilirubin in the first 2weeks, and review at 4-6weeks.

We retrospectively reviewed $52 \mathrm{DCT}+$ neonates born at $\mathrm{RHH}$ between May 2008 and June 2009 to assess their outcome and to evaluate the need to review the current guideline. We divided the sample into three groups. Group 1: Rh isoimmunisation due to $\mathrm{RhD}$ (39/52), 2: other $\mathrm{Rh}$ and non $\mathrm{Rh}$ alloimmunization (6/52) and 3: with $\mathrm{ABO}$ incompatibility $(7 / 52)$.

In group $1,38 / 39$ mothers received anti-D prophylaxis(RAADP). $20 / 39$ had weakly positive and $19 / 39$ had moderately DCT+. None of these neonates developed anaemia or prolonged jaundice.

In group $2(n=6), 3 / 6$ were strongly DCT + and $2 / 3$ developed jaundice $<24$ hours requiring phototherapy. $3 / 6$ showed moderately DCT + and 2 required phototherapy in the first week. At 2 weeks $4 / 6$ developed anaemia but did not warrant transfusion.

In group 3(n=7), 6 showed moderate DCT + and 1 weakly DCT+. $5 / 7$ in group 3 received phototherapy in the first week. 5/7 in group 2 developed prolonged jaundice. $1 / 7$ at 2 weeks showed anaemia.

We conclude that

1. Neonates born to mothers who received RAPPD do not show significant post delivery haemolysis and may not require close monitoring

2. Those with non RhD alloimmunisation and $A B O$ incompatibility require monitoring for haemolysis at 2 weeks and review at 6 weeks

3. Although small number in our study, strong positive DCT warrants close monitoring in the first 24 hours of age.

\section{LINEAR GROWTH AND CIRCULATING IGF-I CONCENTRATIONS IN CHILDREN WITH IRON DEFICIENCY ANEMIA AFTER TREATMENT}

doi:10.1136/archdischild-2012-302724.0765

A Soliman, M Eldabbagh, A Adel, A Sabt. Pediatrics, Hamad Medical Center, Doha, Oatar

Objective To assess linear growth of patients with Fe deficiency anemia (IDA) before and after in relation to their hematologic parameters and IGF-I concentration before and after treatment with iron.

Methods Forty children (aged $17.2+/-12.4$ ) months with iron deficiency anemia were studied with 40 healthy normal agematched children (controls). Patients were treated with iron syrup or drops to supply $6 \mathrm{mg} / \mathrm{kg} /$ day. Growth (weight, length and headcircumference) and hematological parameters were measured and IGF-I concentrations measured before and 3 and 6 months after treatment.

Results Growth parameters (weight, length and head-circumference) and hematological parameters were studied for 6 months after iron therapy. At presentation, patients with IDA had low $\mathrm{Hb}(8.2$ $+/-1.2 \mathrm{~g} / \mathrm{dl})$, hematocrit $(29+/-2.8)$, MCV $(61.5+/-8.1)$, and $\mathrm{MCH}(19+/-3.2)$ which improved significantly after treatment to $(11.2+/-1 \mathrm{~g} / \mathrm{dl}, 70.6+/-6.8,23.4+/-2.9$ and $18.9+/-5$ respectively). Before treatment children with iron deficiency they had length standard deviation score (LSDS) $=-1.2+/-1$, annualized growth velocity $(\mathrm{GV})=7.5+/-2.2$, GV SDS $=-1.42+/-0.6$ and $\mathrm{BMI}$ $=13.5+/-1.2$. After 6 months their LSDS $=-0.6+/--0.9$, annualized GV $=13.2+/-4.4 \mathrm{~cm} /$ year, GVSDS $=1.7+/-0.5$, and $\mathrm{BMI}=14.2$ $+/-1.1)$. Circulating IGF-I increased significantly after treatment $(52+/-18.8 \mathrm{ng} / \mathrm{ml})$ vs before treatment $(26.5+/-4.2 \mathrm{ng} / \mathrm{ml})$.

\section{A REVIEW OF TOLERATION OF PNUEMOCYSTIS CARINII PNEUMONITIS (PCP) PROPHYLAXIS TREATMENT IN CHILDREN WITH ACUTE LYMPHOBLASTIC LEUKAEMIA}

doi:10.1136/archdischild-2012-302724.0766

PM O'Hare, A Moody, T Zerb, D Lancaster. Paediatric Oncology, Royal Marsden Hospital, London, UK

Background and Aims According to the UKALL2003 protocol, co-trimoxazole should be used as first line therapy to prevent PCP 